\title{
Pre-treatment of the paper pulp in the bleaching process using biodegradable chelating agents
}

\author{
I. S. S. Pinto • O. S. Ascenso • M. T. Barros • \\ H. M. V. M. Soares
}

Received: 1 July 2013/Revised: 3 November 2013/Accepted: 9 December 2013/Published online: 20 December 2013

(C) Islamic Azad University (IAU) 2013

\begin{abstract}
The aim of this work was to study the application of two biodegradable chelating agents, pyridine-2,6dicarboxylic acid (PDA) and methylglycinediacetic acid (MGDA), in the treatment of the pulp, prior to hydrogen peroxide bleaching. Such compounds must remove transition metals $(\mathrm{Mn}, \mathrm{Fe}$ and $\mathrm{Cu}$ ) from pulp, that catalyze the degradation of hydrogen peroxide, and $\mathrm{Ca}$, which is also problematic due to the formation of precipitates that accumulate in the equipment. Computer simulations were first performed to study the best conditions for metal complexation, and optimum $\mathrm{pH}$ was defined as 5-5.5 for PDA and 6.5-7 for MGDA. Metals removal from the pulp, as well as the subsequent bleaching process (Q-P1-Paa-P2), were tested experimentally, and performances were compared to ethylenediaminetetracetic acid (EDTA). PDA removed both $\mathrm{Mn}$ and $\mathrm{Ca}$ efficiently, leaving most $\mathrm{Mg}$ in the pulp after first chelation stage, while MGDA had a lower $\mathrm{Ca}$ removal, even using a higher $\mathrm{pH}$ and concentration. Residual hydrogen peroxide and kappa number after peroxide stages showed a similar bleaching efficiency between the studied compounds and EDTA.
\end{abstract}

Keywords Bleaching - Chelating agents . Methylglycinediacetic acid · Paper pulp · Pyridine-2,6dicarboxylic acid (dipicolinic acid)

\section{S. S. Pinto · H. M. V. M. Soares ( $₫)$}

REQUIMTE, Departamento de Engenharia Química, Faculdade de Engenharia, Universidade do Porto, Rua Dr. Roberto Frias, 4200-465 Porto, Portugal

e-mail: hsoares@fe.up.pt

O. S. Ascenso - M. T. Barros

REQUIMTE, CQFB, Departamento de Química, Faculdade de Ciência e Tecnologia, Universidade Nova de Lisboa,

2829-516 Caparica, Portugal

\section{Introduction}

During the last decades, the pulp industry made several changes in the paper pulp bleaching process in order to minimize environmental impacts. Some of the current processes are chlorine free, giving preference to oxygenbased oxidants such as ozone, hydrogen peroxide, molecular oxygen and peracids (Ni and Liu 2000). Hydrogen peroxide is widely used as bleaching agent in paper manufacture. However, the presence of transition metals, such as iron $(\mathrm{Fe})$, manganese $(\mathrm{Mn})$ and copper $(\mathrm{Cu})$, affects the efficiency of the oxidizing agent because they catalyze the degradation of hydrogen peroxide. These metals are in the process as impurities of chemicals used in the bleaching, washing waters and wood itself and the control of its presence is very important to minimize hydrogen peroxide degradation and maximize bleaching efficiency (Wuorimaa et al. 2006). On the other hand, the presence of magnesium $(\mathrm{Mg})$ in the bleaching step is important to stabilize the metal ions that increase peroxide degradation (Colodette et al. 1989; Abbot and Brown 1990).

The control of metals in the bleaching stages can be achieved through several ways (Area and Felissia 2005; Povoas et al. 2012). Ethylenediaminetetracetic acid (EDTA) and diethyleneaminepentacetic acid (DTPA) are the most employed chelating agents to overcome the problems caused by the presence of metals in the bleaching process of pulp with hydrogen peroxide (Jones and Williams 2002; Hyvonen et al. 2006). The chelating agent is usually added to the pulp during the chelation stage, before the peroxide stage, and the metals present in the pulp are solubilized due to the formation of complexes and removed along with water (Ni and Liu 2000). Although EDTA and DTPA are compounds with a good-quality/price ratio that leads to the desired results in the bleaching process because 
<smiles>CC(C(=O)O)N(CC(=O)O)CC(=O)O</smiles><smiles>O=C(O)c1cccc(C(=O)O)n1</smiles>

Fig. 1 Structure of pyridine-2,6-dicarboxylic acid (PDA) and methylglycinediacetic acid (MGDA)

of its strong affinity for metal ions, its use is questioned due to environmental reasons as they do not fulfill the OECD biodegradability criteria (OECD 1992). The waste water treatment plants are not able to degrade EDTA and DTPA and several environmental concerns arise due to the perturbation of the natural speciation of metals in the aquatic resources (Bucheli-Witschel and Egli 2001). Another consequence is the possible contribution for the eutrophization of the aquatic resources due to the nitrogen present in both EDTA (two atoms) and DTPA (three atoms) molecules (Sillanpaa et al. 1995).

The most studied replacers for EDTA in the paper pulp industry, so far, are the ethylenediamine- $N, N^{\prime}$-disuccinic acid (EDDS) and iminodisuccinic acid (IDS) (Hyvonen et al. 2006; Jones and Williams 2001, 2002; Renvall et al. 1997; Seccombe and Dournel 2007). EDDS, especially the $[S, S]$ isomer, seems to be the most suitable alternative for EDTA because it combines chelation efficiency and readybiodegradability. However, studies regarding new alternatives continued to be held to obtain a high-efficient, environmental-friendly, competitive chelating agent to be used in the paper pulp industry (Hyvonen et al. 2006; Metsarinne et al. 2007).

Calcium $(\mathrm{Ca})$ is present in large quantities in the process due to high concentrations of this metal in water and wood; nevertheless, it does not cause any effect in the catalysis of hydrogen peroxide decomposition. Although authors, such as Jones and Williams (2001) and Hyvonen et al. (2006), consider that the removal of $\mathrm{Ca}$ is a disadvantage because it wastes the chelating agent, the existence of calcium in hydrogen peroxide bleaching can lead to precipitates, mainly oxalate and carbonate, that accumulate in the equipment, forming scale that is hard to remove (Rudie 2000). The presence of chelating agents, such as EDTA and DTPA, can help to increase the solubility of calcium oxalate (Elsander et al. 2000).

Methylglycinediacetic acid (MGDA) (Fig. 1) is a chelating agent, biodegradable and non-toxic (Knepper 2003;
Bucheli-Witschel and Egli 2001), derived from nitrilotriacetic acid (NTA). It can be used in several commercial applications, such as scale prevention (List and Reinbold 2010) and cleaning (Jefferis and Zack 2011). Dournel (2009), Seccombe (2008) and De Almeida et al. (2008) mentioned the application of MGDA in the pulp bleaching process, but no experiments were performed concerning this compound.

Pyridine-2,6-dicarboxylic acid (PDA), also known as dipicolinic acid (Fig. 1), is a constituent of bacterial spores. PDA revealed to be a ready-biodegradable compound according to the OECD guidelines (Martins et al. 2014), and due to its ability to complex with metal ions, it has been studied for remediation of soils (Macauley and Hong 1995; Hong and Chen 1996), used in detergents and cleaning applications (Rattinger et al. 1994; Boskamp 1990). It is mentioned as a component of a bleaching composition by Turner et al. (1997), but the study was focused on the textile bleaching and was used in a hydrogen peroxide composition together with other compounds.

Besides being biodegradable, both compounds (MGDA and PDA) have the advantage of containing just one nitrogen atom per molecule, which makes them more environmentally friendly. The present work was focused on the application of these two biodegradable chelating agents in the paper pulp bleaching process. Primarily, computer chemical simulations were performed to evaluate the ability to complex metal ions and optimize experimental conditions. The process was applied in Eucalyptus Globulus pulp via O-Q-P1-Paa-P2 sequence, and important parameters such as metal removal, peroxide consumption and kappa number were determined and compared to a situation using EDTA. This research was carried out during 2010-2011 at the REQUIMTE laboratory in the Chemical Engineering Department of the Faculty of Engineering, University of Porto, Portugal.

\section{Materials and methods}

Synthesis of pyridine-2,6-dicarboxylic acid

There are several methods present in the literature for the preparation of PDA. In general, the global yield is low or there is a necessity of complex purification processes. The present experimental protocol was developed based on the works of Xiao et al. (2008), Black et al. (1949) and Singer and McElvain (1955) where 2,6-dimethylpyridine is oxidized with potassium permanganate (Fig. 2).

Potassium permanganate (99\%) was added (5.9 g, $37.33 \mathrm{mmol})$ to 2,6-dimethylpyridine (99\%) (1 g, $9.33 \mathrm{mmol}$ ) in $25 \mathrm{~mL} \mathrm{H}_{2} \mathrm{O}$. The resulting mixture was stirred at $100{ }^{\circ} \mathrm{C}$. After $4 \mathrm{~h}$, the solution was slowly cooled 

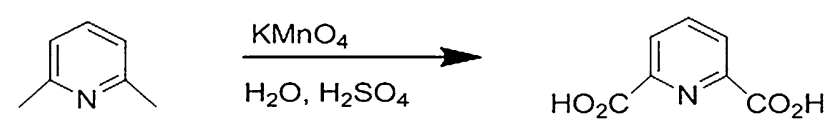

Fig. 2 Schematic representation for the synthesis of PDA

to room temperature and filtered. $\mathrm{H}_{2} \mathrm{SO}_{4}(70 \%)$ was added and stirred at $60{ }^{\circ} \mathrm{C}$. After $15 \mathrm{~min}$, the solution was cooled to room temperature. The formed precipitate was filtered and recrystallized in $\mathrm{H}_{2} \mathrm{O}$, to give the desired product as a pure white solid.

The following improvements were achieved, when compared to the literature (Xiao et al. 2008; Black et al. 1949; Singer and McElvain 1955):

1. The volume of water was reduced from 50 to $25 \mathrm{~mL} / \mathrm{g}$ of the starting material; this modification eliminated the concentration under vacuum step, which allows an easier scale up.

2. Hydrochloric acid was replaced by sulfuric acid, which allowed better yields.

3. The amount of potassium permanganate was reduced from 5 to 4 eq, which saved reagents.

Final product was obtained with a global yield $\geq 70 \%$ and purity was $\geq 97 \%$.

Melting point (MP) values were determined with a capillary apparatus and are uncorrected. NMR spectra were recorded on a Bruker AMX-400 MHz spectrophotometer, in $\left(\mathrm{CD}_{3}\right)_{2} \mathrm{SO}$, using the water residual peak as internal standard (4.79 $\mathrm{ppm})$. Structural assignment of all compounds was made by bidimensional NMR techniques (COSY and HMQC): 2D NMR (COSY 45 and HMQC) spectra were recorded by using standard pulse sequences and parameters recommended by the manufacturer.

${ }^{1} \mathrm{H}$ NMR $\left(400 \mathrm{MHz},\left(\left(\mathrm{CD}_{3}\right)_{2} \mathrm{SO}\right) \delta 8.24-8.15(\mathrm{~m}, 3 \mathrm{H})\right.$

${ }^{13} \mathrm{C}$ NMR $\left(100 \mathrm{MHz},\left(\left(\mathrm{CD}_{3}\right)_{2} \mathrm{SO}\right) \delta 165.43,148.08\right.$, $139.20,127.47$

IR: $1759(\mathrm{C}=\mathrm{O})$

MP: $242-243{ }^{\circ} \mathrm{C}$.

\section{Computer chemical simulations}

Computer simulations were performed to study the metalschelant systems and optimize conditions for metal removal from the pulp.

Chemical speciation calculations were carried out using the MINEQL+ software (version 4.5) (Schecher and McAvoy 2003). Metal speciation analysis with MINEQL+ generates chemical equilibrium concentrations of all species being considered in the model by the program reactions, based on component stability constants (Martell and Smith 2004) and molar metal concentrations. For computer
Table 1 Protonation and overall stability constants of EDTA, MGDA and PDA with $\mathrm{Fe}, \mathrm{Mn}, \mathrm{Cu}, \mathrm{Ca}$ and $\mathrm{Mg}$ ions, at $25^{\circ} \mathrm{C}$, in $\mu=0.1 \mathrm{M}$ (Martell and Smith 2004) unless otherwise stated

\begin{tabular}{|c|c|c|c|c|}
\hline & Reaction & EDTA & MGDA & PDA \\
\hline \multirow[t]{5}{*}{$\mathrm{H}^{+}$} & $\mathrm{H}+\mathrm{L} \leftrightarrow \mathrm{HL}$ & 9.5 & 9.9 & 4.7 \\
\hline & $2 \mathrm{H}+\mathrm{L} \leftrightarrow \mathrm{H}_{2} \mathrm{~L}$ & 15.6 & 12.4 & 6.7 \\
\hline & $3 \mathrm{H}+\mathrm{L} \leftrightarrow \mathrm{H}_{3} \mathrm{~L}$ & 18.3 & 13.9 & \\
\hline & $4 \mathrm{H}+\mathrm{L} \leftrightarrow \mathrm{H}_{4} \mathrm{~L}$ & 20.3 & & \\
\hline & $5 \mathrm{H}+\mathrm{L} \leftrightarrow \mathrm{H}_{5} \mathrm{~L}$ & 21.8 & & \\
\hline \multirow[t]{4}{*}{$\mathrm{Fe}^{3+}$} & $\mathrm{M}+\mathrm{L} \leftrightarrow \mathrm{ML}$ & 25.1 & $16.5^{\mathrm{a}}$ & 10.9 \\
\hline & $\mathrm{M}+2 \mathrm{~L} \leftrightarrow \mathrm{ML}_{2}$ & & & 17.1 \\
\hline & $\mathrm{M}+\mathrm{H}+\mathrm{L} \leftrightarrow \mathrm{MHL}$ & 26.4 & & \\
\hline & $\mathrm{M}+\mathrm{L} \leftrightarrow \mathrm{M}(\mathrm{OH}) \mathrm{L}+\mathrm{H}^{+}$ & 17.7 & & \\
\hline \multirow[t]{3}{*}{$\mathrm{Mn}^{2+}$} & $\mathrm{M}+\mathrm{L} \leftrightarrow \mathrm{ML}$ & 13.9 & $8.4^{\mathrm{a}}$ & 5.0 \\
\hline & $\mathrm{M}+2 \mathrm{~L} \leftrightarrow \mathrm{ML}_{2}$ & & & 8.5 \\
\hline & $\mathrm{M}+\mathrm{H}+\mathrm{L} \leftrightarrow \mathrm{MHL}$ & 17.0 & & \\
\hline \multirow[t]{4}{*}{$\mathrm{Cu}^{2+}$} & $\mathrm{M}+\mathrm{L} \leftrightarrow \mathrm{ML}$ & 18.8 & $13.9^{\mathrm{a}}$ & 9.1 \\
\hline & $\mathrm{M}+2 \mathrm{~L} \leftrightarrow \mathrm{ML}_{2}$ & & & 16.4 \\
\hline & $\mathrm{M}+\mathrm{H}+\mathrm{L} \leftrightarrow \mathrm{MHL}$ & 21.9 & & \\
\hline & $\mathrm{M}+\mathrm{L} \leftrightarrow \mathrm{M}(\mathrm{OH}) \mathrm{L}+\mathrm{H}^{+}$ & 7.4 & & 1.6 \\
\hline \multirow[t]{3}{*}{$\mathrm{Ca}^{2+}$} & $\mathrm{M}+\mathrm{L} \leftrightarrow \mathrm{ML}$ & 10.7 & $7.0^{\mathrm{a}}$ & 4.4 \\
\hline & $\mathrm{M}+2 \mathrm{~L} \leftrightarrow \mathrm{ML}_{2}$ & & & 7.4 \\
\hline & $\mathrm{M}+\mathrm{H}+\mathrm{L} \leftrightarrow \mathrm{MHL}$ & 12.8 & & \\
\hline \multirow[t]{3}{*}{$\mathrm{Mg}^{2+}$} & $\mathrm{M}+\mathrm{L} \leftrightarrow \mathrm{ML}$ & 8.8 & $5.8^{\mathrm{a}}$ & 2.3 \\
\hline & $\mathrm{M}+2 \mathrm{~L} \leftrightarrow \mathrm{ML}_{2}$ & & & 3.0 \\
\hline & $\mathrm{M}+\mathrm{H}+\mathrm{L} \leftrightarrow \mathrm{MHL}$ & 12.8 & & \\
\hline
\end{tabular}

${ }^{a}$ BASF 2007

simulations, molar metal concentrations were calculated considering the total content of metals in the pulp ( $10 \mathrm{~g}$ of pulp with $35 \%$ consistency in $50 \mathrm{~mL}$ solution) and a chelant concentration of $2 \times 10^{-3} \mathrm{~mol} / \mathrm{L}$.

The reactions considered in the simulation were the formation of metal $(\mathrm{Mn}, \mathrm{Fe}, \mathrm{Cu}, \mathrm{Ca}$ and $\mathrm{Mg}$ ) hydroxocomplexes (Martell and Smith 2004) and complexes between the chelating agents and metals (Table 1). The prediction of the species distribution was calculated using the titration mode, between $\mathrm{pH} 3$ and 12, with a step of 0.5 .

Chelation studies and bleaching process

Oxygen-delignified paper pulp (E. globulus) was obtained from a Portuguese pulp mill. Dry content, metal content and kappa number (TAPPI 236) were determined for the initial pulp. Aqueous solutions of chelating agents were prepared from $\mathrm{Na}_{2}$ EDTA $2 \mathrm{H}_{2} \mathrm{O}$ (Titriplex ${ }^{\circledR}$ III p.a., Merck), $\mathrm{Na}_{3}$ MGDA (Trilon ${ }^{\circledR}$ M powder, BASF) or synthesized PDA.

To study the ability of chelants to complex with the metals present in the pulp, about $10 \mathrm{~g}$ of pulp (35\% dry content) was mixed with $50 \mathrm{~mL}$ of chelant aqueous 
solution $\left(\sim 70 \mathrm{~kg}\right.$ odp $/ \mathrm{m}^{3}$; odp $=$ oven dried pulp), and $\mathrm{pH}$ was corrected by addition of $\mathrm{HCl}$ or $\mathrm{NaOH}$. Experiments were performed in a thermostatic bath at $80{ }^{\circ} \mathrm{C}$, for $90 \mathrm{~min}$. Then, the mixture was filtered and metals concentrations were analyzed using atomic absorption spectroscopy with flame atomization (AAS-FA) in a PerkinElmer AAnalyst 400 spectrometer (Norwalk, CT, USA). Each experiment was performed in triplicate.

The subsequent bleaching process was tested for the chosen conditions, using the same consistency of the previous chelation stage (stage $\mathrm{Q}$ ). The bleaching sequence started with stage $\mathrm{Q}$ followed by peroxide bleaching (stage P1), peracetic acid with chelant charge (stage Paa) and a second stage with hydrogen peroxide (stage P2):

Stage $\mathrm{P} 1-80{ }^{\circ} \mathrm{C}, 2 \mathrm{~h}, \quad \mathrm{H}_{2} \mathrm{O}_{2} 18 \mathrm{~kg} /$ ton odp, $\mathrm{NaOH}$ $5 \mathrm{~kg} /$ ton odp.

Stage Paa $-80{ }^{\circ} \mathrm{C}, 2 \mathrm{~h}$, peracetic acid $12 \mathrm{~kg} /$ ton odp, chelating agent: half of the quantity used in stage $\mathrm{Q}$.

Stage $\mathrm{P} 2-90{ }^{\circ} \mathrm{C}, 3 \mathrm{~h}, \mathrm{H}_{2} \mathrm{O}_{2} 28 \mathrm{~kg} /$ ton odp, $\mathrm{NaOH}$ $10 \mathrm{~kg} /$ ton odp.

After each stage, the pulp was filtered and washed with deionized water. The $\mathrm{pH}$ of the filtrates was controlled throughout the process. Metal content in the filtrate was determined after stages $\mathrm{Q}$ and Paa using AAS-FA. For stages $\mathrm{P} 1$ and $\mathrm{P} 2$, total consumption of peroxide was determined in the filtrate by iodometry and the pulp obtained was characterized for kappa number (TAPPI 236). Each experiment was performed in triplicate.

\section{Results and discussion}

Metals removal from pulp:Stage Q

\section{Computer chemical simulations}

The metal content of the initial paper pulp is presented in Table 2. Values are close to what can be found in the literature although $\mathrm{Mn}$ is quite low (Area and Felissia 2005; Povoas et al. 2012; Jones and Williams 2001). This was

Table 2 Metal content in the initial pulp

\begin{tabular}{lllr}
\hline Metal & Content (g/odt) & Content (mol/odt) & \multicolumn{1}{l}{$\begin{array}{l}\text { Concentration } \\
\text { (mol/L) }\end{array}$} \\
\hline $\mathrm{Fe}$ & $18 \pm 2$ & 0.32 & $2.2 \times 10^{-5}$ \\
$\mathrm{Mn}$ & $14.8 \pm 0.9$ & 0.27 & $1.9 \times 10^{-5}$ \\
$\mathrm{Cu}$ & $\leq 1.5$ & 0.023 & $\leq 1.6 \times 10^{-6}$ \\
$\mathrm{Ca}$ & $764 \pm 59$ & 19 & $1.3 \times 10^{-3}$ \\
$\mathrm{Mg}$ & $104 \pm 7$ & 4.3 & $3.0 \times 10^{-4}$ \\
\hline
\end{tabular}

a $10 \mathrm{~g}$ of pulp (35\% dry content) in $50 \mathrm{~mL}$ of solution observed because the pulp was collected after oxygen prebleaching and a significant quantity of Mn is washed during this stage (Loureiro et al. 2011).

Considering the metal content and the consistency mentioned in "Experimental" section $\left(70 \mathrm{~kg}\right.$ odp $\left./ \mathrm{m}^{3}\right)$, molar concentration of each metal was calculated (Table 2) in order to study complexation using computer chemical simulations.

Computer simulations were performed in order to understand the ability of the compounds to complex with the metals. To compare different compounds, independently of their molar mass, the quantity of chelating agent was calculated in a molar basis. The total quantity of chelating agent to be used must be at least equal to the sum of all the metals to be removed: $\mathrm{Fe}, \mathrm{Mn}$ and $\mathrm{Cu}$, to prevent peroxide degradation during bleaching, and $\mathrm{Ca}$, to avoid scale complications due to its precipitation as oxalate and carbonate. Therefore, a chelant (Q) concentration of $2 \times 10^{-3} \mathrm{~mol} / \mathrm{L}$ was considered. Computer simulations were performed taking into account the complex formation between the chelating agent and the metals (Table 1); however, interactions between metals and fibers or other compounds present in the pulp were not considered.

Due to the very low content of $\mathrm{Cu}$ in the pulp and its usual high affinity with chelating agents, results for this metal are not presented. However, simulations were performed and total $(100 \%)$ complexation throughout almost the whole $\mathrm{pH}$ range was predicted for the three chelating agents studied.

Figure 3 shows the ability of MGDA and PDA, at $2 \times 10^{-3} \mathrm{~mol} / \mathrm{L}$, to bind with the different metals present in the paper pulp and results are compared to EDTA. Computer simulation predicts that both MGDA and PDA are able to complex $\mathrm{Ca}$ and $\mathrm{Mn}$ completely. In the case of MGDA (Fig. 3a), maximum complexation of $\mathrm{Mn}$ is expected to occur for $\mathrm{pH}$ higher than 6 , while for $\mathrm{Ca}$, a $\mathrm{pH}$ of at least 7.5 is needed. However, $\mathrm{pH}$ values higher than 7 are not advisable due to the higher affinity of metals with the charged groups present in the fibers that compete with the ligands and thus difficult metals removal (Povoas et al. 2012; Chandraghargi 2003). Additionally, the Q stage of the pulp must occur between $\mathrm{pH} 4$ and 7 for optimum brightness after the $\mathrm{P}$ stage (Bajpai 2012). If we increase the concentration of MGDA to $4 \times 10^{-3} \mathrm{~mol} / \mathrm{L}$ (data not shown), the predicted behavior does not change significantly; however, the amount of complexed $\mathrm{Ca}$ reaches values higher than $90 \%$ at $\mathrm{pH}$ 6.5, unlike what happened for the lower chelating concentration. Although a $\mathrm{pH}$ between 6.5 and 7 can promote $\mathrm{Mn}$ and $\mathrm{Ca}$ chelation, simulation evidences that $\mathrm{pH} 6.5$ is not suitable for $\mathrm{Fe}$ removal, which is a drawback for complete removal of harmful metals. Nevertheless, since Mn is the most critical metal ion for hydrogen peroxide decomposition (Lapierre 


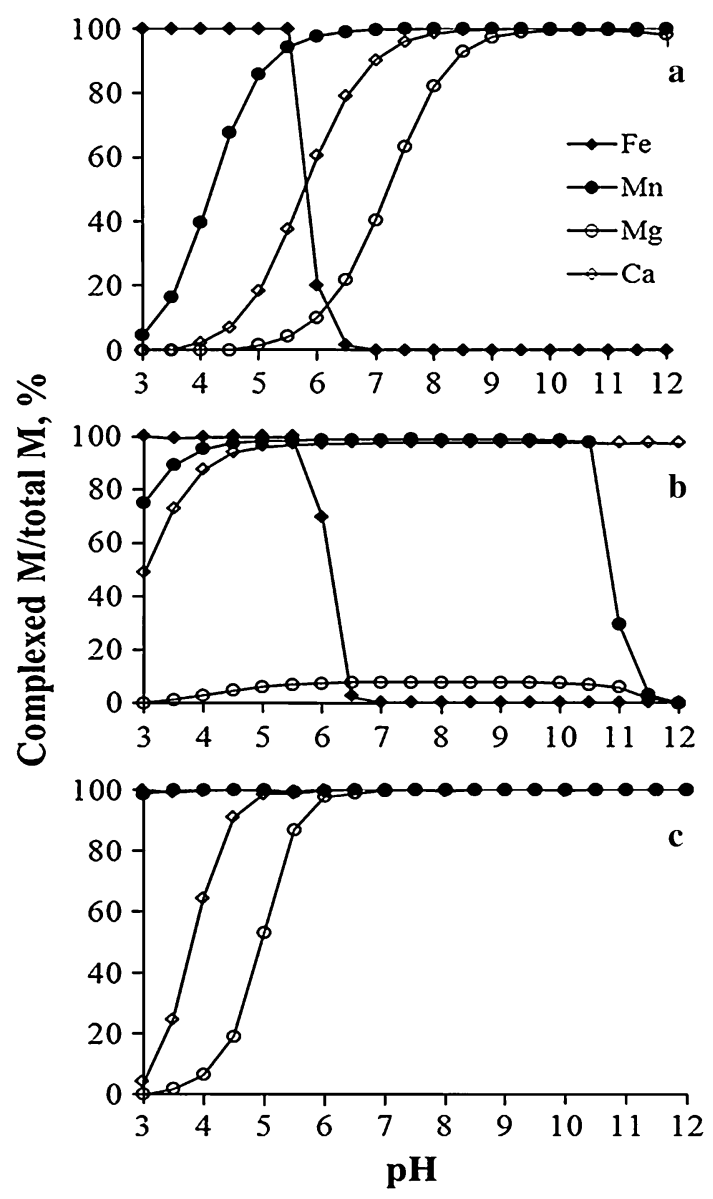

Fig. 3 Percentage of complexed metal ( $\mathrm{Mn}, \mathrm{Fe}, \mathrm{Mg}$ and $\mathrm{Ca}$ ), predicted by computer simulations, considering an aqueous solution with $\quad \mathrm{Fe}=2.2 \times 10^{-5} \mathrm{~mol} / \mathrm{L}, \quad \mathrm{Mn}=1.9 \times 10^{-5} \mathrm{~mol} / \mathrm{L}$, $\mathrm{Ca}=1.3 \times 10^{-3} \mathrm{~mol} / \mathrm{L}, \quad \mathrm{Mg}=3.0 \times 10^{-4} \mathrm{~mol} / \mathrm{L} \quad$ and $\mathrm{Q}=2 \times 10^{-3} \mathrm{~mol} / \mathrm{L}$, where $\mathrm{Q}$ is MGDA (a), PDA (b) or EDTA (c)

et al. 2003), priority must be given to its removal. Simulation also evidences that MGDA complexes a high amount of $\mathrm{Mg}$, which might be another disadvantage, because the presence of $\mathrm{Mg}$ in the pulp might be beneficial in the peroxide stage (Colodette et al. 1989; Abbot and Brown 1990). A pH between 6.5 and 7 was defined to proceed to the experimental tests.

Under the same conditions, PDA has the advantages of having low affinity for $\mathrm{Mg}$ and being able to complex $\mathrm{Ca}$ at lower $\mathrm{pH}$ values (Fig. $3 \mathrm{~b}$ ). Simulation predicts that at $\mathrm{pH}$ values between 4.5 and 5.5, $\mathrm{Fe}, \mathrm{Mn}$ and $\mathrm{Ca}$ should be totally removed by PDA. When PDA concentration is increased to $4 \times 10^{-3} \mathrm{~mol} / \mathrm{L}$ (data not shown), this situation is extended until $\mathrm{pH} 6$, but $\mathrm{Mg}$ complexation also increases. A pH between 5 and 5.5 was defined to proceed to the experimental tests.

EDTA has a high affinity for all the metals considered, with total complexation of $\mathrm{Fe}$ and $\mathrm{Mn}$ in the $\mathrm{pH}$ range studied while $\mathrm{Ca}$ is totally complexed above $\mathrm{pH} 5$ and $\mathrm{Mg}$ above $\mathrm{pH} 6$.
Table 3 Experimental conditions and respective metal removal for the pre-treatment of the pulp $\left(80^{\circ} \mathrm{C}, 90 \mathrm{~min}\right)$

\begin{tabular}{llllll}
\hline Compound & $\begin{array}{l}\text { Concentration } \\
(\mathrm{mol} / \mathrm{L})\end{array}$ & $\mathrm{pH}$ & \multicolumn{3}{l}{$\begin{array}{l}\text { Metal removed } \\
\text { from the pulp (\%) }\end{array}$} \\
\cline { 3 - 6 } \cline { 3 - 6 } & & & $\mathrm{Mn}$ & $\mathrm{Ca}$ & $\mathrm{Mg}$ \\
\hline Water & - & 5.5 & $34 \pm 3$ & $23 \pm 2$ & $35 \pm 2$ \\
EDTA & $2.0 \times 10^{-3}$ & $5.5-6.0$ & $101 \pm 2$ & $99 \pm 2$ & $66 \pm 5$ \\
PDA & $4.4 \times 10^{-3}$ & $5.0-5.5$ & $102 \pm 5$ & $86 \pm 3$ & $35 \pm 3$ \\
& $2.0 \times 10^{-3}$ & $5.0-5.5$ & $99 \pm 1$ & $93 \pm 2$ & $37 \pm 3$ \\
MGDA & $3.7 \times 10^{-3}$ & $6.5-7.0$ & $103 \pm 3$ & $70 \pm 2$ & $69 \pm 7$
\end{tabular}

Experiments were performed in triplicate and corresponding standard deviations are presented

\section{Metal removal}

The removal of metals from the paper pulp was tested experimentally and results are presented in Table 3. PDA and MGDA were tested using concentrations between $2 \times 10^{-3}$ and $4.5 \times 10^{-3} \mathrm{~mol} / \mathrm{L}$. Experiments with EDTA were also performed within this concentration range as a term of comparison.

$\mathrm{Mn}$ is the most harmful metal present in the pulp for hydrogen peroxide. For all conditions studied (Table 3), removal of Mn was efficient, as it was predicted by the simulations. $\mathrm{Cu}$ removal was not included because the values were below the detection limit of the AAS-FA equipment. The Fe removal from the pulp was not very significant with values around 20-30\% (data not shown) regardless of which chelating agent was used. From the computer simulations (Fig. 3), where only metal-ligand interactions in aqueous solution were considered, a higher dissolution of $\mathrm{Fe}$ was expected at least in the case where EDTA was used, due to the high-stability constant of the Fe-EDTA complex (Table 1). However, $\mathrm{Fe}$ is strongly attached to the pulp, the composition of which was not considered in the computer simulations, and in other bleaching studies, a lower removal of Fe from the pulp through the various stages was also attained (Loureiro et al. 2011; Potucek and Milichovsky 2000; Kujala et al. 2004).

Concerning the removal of $\mathrm{Ca}$ from the pulp, EDTA was efficient, which means that the presence of $\mathrm{Ca}$ from the pulp in further stages of the process is highly reduced, thus reducing the formation of calcium scale.

In the case of MGDA, the simulation for $2 \times 10^{-3} \mathrm{~mol} / \mathrm{L}$ did not predict complete removal of $\mathrm{Ca}$ at $\mathrm{pH}$ 6.5-7 (Fig. 3), so, a higher concentration, close to $4 \times 10^{-3} \mathrm{~mol} / \mathrm{L}$, was experimentally attempted (Table 3 ). Nevertheless, Ca dissolution from the pulp only reached $70 \%$ and a significant quantity of $\mathrm{Mg}$ was also removed, as expected from the simulations (Fig. 3a), which can be disadvantageous for bleaching. 
For PDA, two different concentrations $\left(2 \times 10^{-3}\right.$ and $4 \times 10^{-3} \mathrm{~mol} / \mathrm{L}$ ) were tested. Both situations led to similar values of metals removal, with almost complete extraction of $\mathrm{Ca}$, as predicted, proving that $2.0 \times 10^{-3} \mathrm{~mol} / \mathrm{L}$ of PDA is enough to remove both $\mathrm{Ca}$ and $\mathrm{Mn}$. Lower concentrations of PDA would not have sufficient molar quantity of chelating agent to complex with these two metals. Table 3 also evidences that using different PDA concentrations, the quantity of $\mathrm{Mg}$ present in the filtrate was very similar, although for the less concentrated solution, the predicted quantity to be complexed was lower ( $\sim 8 \%$ ) (Fig. 3b). Experiments with water explain well these results (Table 3 ) because even when no chelating agent was added, $35 \%$ of $\mathrm{Mg}$ was leached from the pulp. The tests with water show the percentage of metal, which is just solubilized from the pulp and not extracted by chelation. This behavior is probably due to the fact that the metals are linked to the pulp by weaker bonds.

\section{Bleaching sequence}

After the study of the chelation stage, the whole bleaching sequence (Q-P1-Paa-P2) was simulated in the laboratory in order to evaluate the differences of peroxide consumption.
Kappa number was also measured to verify if significant differences in the delignification of the pulp, which are related to the extent of the bleaching, were verified.

The bleaching sequence was studied for MGDA $3.7 \times 10^{-3} \mathrm{~mol} / \mathrm{L}$ and PDA $2.0 \times 10^{-3} \mathrm{~mol} / \mathrm{L}$; a concentration of $2.0 \times 10^{-3} \mathrm{~mol} / \mathrm{L}$ of EDTA was also used for comparative purposes.

$\mathrm{MgSO}_{4}$ is commonly added during peroxide bleaching as a stabilizer, since $\mathrm{Mg}$ deactivates the harmful effect of $\mathrm{Fe}, \mathrm{Cu}$ and $\mathrm{Mn}$, in the presence of the pulp (Wuorimaa et al. 2006). For this study, we preferred not to add any extra $\mathrm{Mg}$ to perceive if different results would be obtained, depending on the $\mathrm{Mg}$ complexed and removed from the pulp.

After P stage, the results of the consumed peroxide and kappa number of the obtained pulp are shown in Table 4. For each assay, the consumed peroxide was corrected for the amount of pulp actually weighted. Additionally, the total amount of $\mathrm{Mg}$ removed during the stages where chelating agent was added was also determined.

During both peroxide bleaching stages, the percentage of consumed peroxide was slightly higher for the MGDA situation; however, considering the standard deviations for

Table 4 Performance of the biodegradable chelating agents, MGDA and PDA, compared to EDTA, for a bleaching sequence Q-P1-Paa-P2

\begin{tabular}{|c|c|c|c|c|c|c|}
\hline & \multirow{2}{*}{$\begin{array}{l}\text { Concentration } \\
(\mathrm{mol} / \mathrm{L})\end{array}$} & \multicolumn{2}{|c|}{ Consumed $\mathrm{H}_{2} \mathrm{O}_{2}(\%)$} & \multicolumn{2}{|c|}{ Kappa number } & \multirow{2}{*}{$\begin{array}{l}\text { Total } \mathrm{Mg} \text { removal } \\
(\%) \mathrm{Q}+\mathrm{Paa}^{\mathrm{a}} \\
\mathrm{Mg}\end{array}$} \\
\hline & & $\mathrm{P} 1$ & $\mathrm{P} 2$ & $\mathrm{P} 1$ & $\mathrm{P} 2$ & \\
\hline MGDA & $3.7 \times 10^{-3}$ & $78 \pm 3$ & $87 \pm 2$ & $4.6 \pm 0.1$ & $3.0 \pm 0.2$ & 93 \\
\hline PDA & $2.0 \times 10^{-3}$ & $75 \pm 5$ & $80 \pm 4$ & $4.6 \pm 0.2$ & $2.4 \pm 0.2$ & 88 \\
\hline EDTA & $2.0 \times 10^{-3}$ & $68 \pm 9$ & $82 \pm 2$ & $5.2 \pm 0.1$ & $2.8 \pm 0.1$ & 90 \\
\hline
\end{tabular}

${ }^{a}$ After Paa stage, calculated in terms of initial metal content

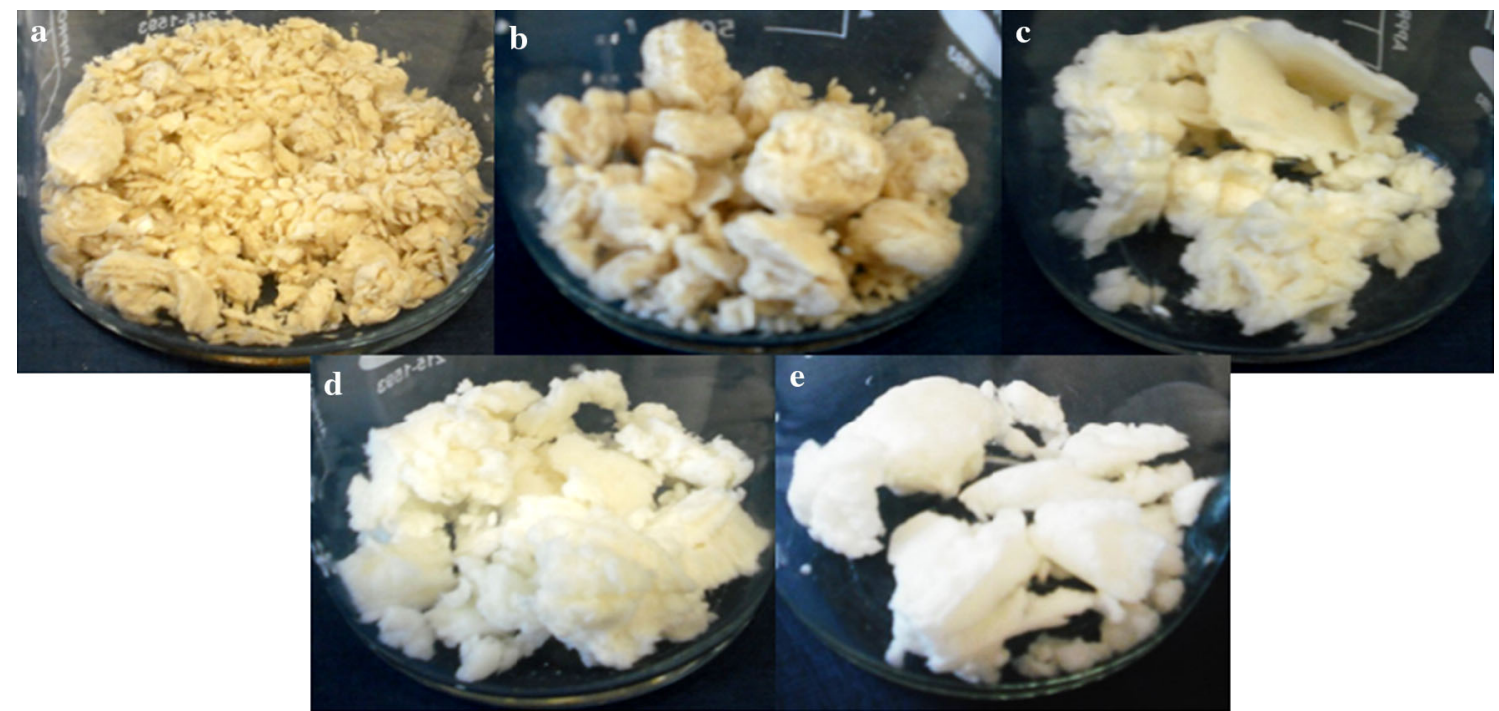

Fig. 4 Appearance of the paper pulp throughout the bleaching process when PDA was used as chelating agent: $\mathbf{a}$ initial, $\mathbf{b}$ after stage Q, $\mathbf{c}$ after stage P1, d after stage Paa, e after stage P2 
the results of stage P1, this difference was only significant for stage P2. Kappa number was very similar among the three situations. For PDA, kappa number was lower for similar peroxide consumptions, which can be due to the lower removal of $\mathrm{Mg}$. Nevertheless, these differences have very little significance.

Figure 4 shows the paper pulp appearance for the different stages of the bleaching process in the sequence where PDA was used as chelating agent. The increase in brightness is evident throughout the bleaching stages, due to the lignin removal, which was also confirmed by the kappa number results.

\section{Conclusion}

MGDA and PDA have been studied, and compared to EDTA, as biodegradable alternatives to remove transition metals and $\mathrm{Ca}$ from the paper pulp by chelation. PDA was able to remove $\mathrm{Mn}$ and $\mathrm{Ca}$ efficiently, leaving most of the $\mathrm{Mg}$ in the pulp, which is advantageous, when compared to EDTA, due to $\mathrm{Mg}$ ability to avoid hydrogen peroxide degradation in the bleaching stage. MGDA also removed Mn completely, but complexation with $\mathrm{Ca}$ was lower than with EDTA or PDA, which is a drawback for scale prevention. Comparison of peroxide consumption during bleaching and kappa number of the pulp has shown that bleaching performance was similar for both chelating agents studied and EDTA. If removal of $\mathrm{Ca}$ from the pulp together with transition metals is intended, PDA might be an alternative option for pre-chelation in pulp bleaching process with hydrogen peroxide, while MGDA is not as efficient for Ca removal.

Acknowledgments This work was financially supported by FEDER funds through the Programa Operacional Factores de Competitividade-COMPETE and national funds by FCT-Fundação para a Ciência e Tecnologia within the Project PTDC-AAC-AMB-111206-2009.

\section{References}

Abbot J, Brown DG (1990) Stabilization of iron-catalyzed hydrogenperoxide decomposition by magnesium. Can J Chem 68:1537-1543

Area MC, Felissia FE (2005) Chelating agents management to obtain TCF bleached Eucalyptus grandis kraft pulps. Appita J 58:143-148

Bajpai P (2012) Environmentally benign approaches for pulp bleaching, 2nd edn. Elsevier, Amsterdam

BASF (2007) Technical information Ti/EVD 1418 e-Trilon ${ }^{\circledR}$ M types

Black G, Depp E, Corson BB (1949) Oxidation of certain methylpyridines to pyridine carboxylic acids. J Org Chem 14:14-21

Boskamp JV (1990) Detergent composition. Patent number EP358472

Bucheli-Witschel M, Egli T (2001) Environmental fate and microbial degradation of aminopolycarboxylic acids. FEMS Microbiol Rev 25:69-106
Chandraghargi RS (2003) Interaction of manganese and copper with wood pulp fibers. Thesis for Master of Applied Science, Department of Chemical and Biological Engineering, University of British Columbia, Vancouver, Canada

Colodette JL, Rothenberg S, Dence CW (1989) Factors affecting hydrogen-peroxide stability in the brightening of mechanical and chemimechanical pulps. II. Hydrogen-peroxide stability in the presence of sodium-silicate. J Pulp Pap Sci 15:3-10

De Almeida JMH, Bachus H, Djodikromo ZP, Doerfler C, Hage R, Lienke J (2008) Bleaching of substrates. Patent number WO2008086937

Dournel P (2009) Process for the bleaching of paper pulp. Patent number WO2009144190

Elsander A, Ek M, Gellerstedt G (2000) Oxalic acid formation during ECF and TCF bleaching of kraft pulp. Tappi J 83:73-77

Hong APK, Chen TC (1996) Chelating extraction and recovery of cadmium from soil using pyridine-2,6-dicarboxylic acid. Water Air Soil Pollut 86:335-346

Hyvonen H, Orama M, Arvelac R, Henriksson K, Saarinen H, Aksela R, Parene A, Jakara J, Renvall I (2006) Studies on three new environmentally friendly chelating ligands. Appita J 59:142-149

Jefferis J, Zack K (2011) Detergent composition. Patent number WO2011100344

Jones PW, Williams DR (2001) Speciation efficiency indices (SEI) and readily-biodegradable indices (RBI) for optimising ligand control of environmental and associated industrial processes. Int J Environ Anal Chem 81:73-88

Jones PW, Williams DR (2002) Chemical speciation simulation used to assess the efficiency of environment-friendly EDTA alternatives for use in the pulp and paper industry. Inorg Chim Acta 339:41-50

Knepper TP (2003) Synthetic chelating agents and compounds exhibiting complexing properties in the aquatic environment. Trac Trend Anal Chem 22:708-724

Kujala M, Sillanpaa M, Ramo J (2004) A method to leach manganese and some other metal cations from pulp matrix to aqueous phase for the subsequent ICP-AES analysis: a potential tool for controlling the metal profile in a pulp bleaching process. J Clean Prod 12:707-712

Lapierre L, Berry R, Bouchard J (2003) The effect of magnesium ions and chelants on peroxide bleaching. Holzforschung 57:627-633

List TC, Reinbold RS (2010) Compositions and methods for removing scale and inhibiting formation thereof. Patent number US2010000579

Loureiro PEG, Evtuguin DV, Carvalho MGVS (2011) The final bleaching of eucalypt kraft pulps with hydrogen peroxide: relationship with industrial ECF bleaching history and cellulose degradation. J Chem Technol Biotechnol 86:381-390

Macauley E, Hong A (1995) Chelation extraction of lead from soil using pyridine-2,6-dicarboxylic acid. J Hazard Mater 40:257-270

Martell AE, Smith RM (2004) NIST standard reference database 46 version 8.0. NIST critically selected stability constants of metal complexes database. US Department of Commerce, National Institute of Standards and Technology

Martins JG, Neto I, Pinto ISS, Soares EV, Barros MT, Soares HMVM (2014) Alternative chelating agents: evaluation of the readybiodegradability and complexation properties. J Environ Sci Health A 49:1-11

Metsarinne S, Ronkainen E, Tuhkanen T, Aksela R, Sillanpaa M (2007) Biodegradation of novel amino acid derivatives suitable for complexing agents in pulp bleaching applications. Sci Total Environ 377:45-51

Ni Y, Liu Z (2000) Pulp bleaching. In: Kirk RE, Othmer DF (eds) Encyclopedia of chemical technology. Wiley, New York 
OECD (1992) Ready biodegradability 301. OECD guideline for testing of chemicals, vol 301

Potucek F, Milichovsky M (2000) Kraft pulp bleaching with hydrogen peroxide and peracetic acid. Chem Pap 54:406-411

Povoas TM, Angelico DAG, Egas APV, Loureiro PEG, GandoFerreira LM, Carvalho MGVS (2012) Prebleaching of eucalypt kraft pulp with OP stages: effect of an acid pretreatment or chelation step. Tappi J 11:31-38

Rattinger GB, Cotter B, Fair MJ (1994) Liquid automatic dishwashing composition. Patent number WO9405763

Renvall I, Askela R, Paren A (1997) Process for bleaching of a high yield pulp. Patent number WO9730209

Rudie A (2000) Calcium in pulping and bleaching. Tappi J 83:36-37

Schecher WD, McAvoy DC (2003) MINEQL+ a chemical equilibrium modeling system, version 4.5 for Windows. User's Manual Hallowell, Maine

Seccombe R (2008) Process for the bleaching of paper pulp. Patent number WO2008101952
Seccombe R, Dournel P (2007) Process for the bleaching of mechanical paper pulp. Patent number WO2007085579

Sillanpaa M, Raimo KB, Sihvonen ML (1995) Determination of Edta and Dtpa as their Fe(III) complexes in pulp and paper-mill process and waste-waters by liquid-chromatography. Anal Chim Acta 303:187-192

Singer AW, McElvain SM (1955) Organic synthesis. Collective 3:740 Turner ET, Moore SB, Leuck JF (1997) Bleaching composition. Patent number US5616280

Wuorimaa A, Jokela R, Aksela R (2006) Recent developments in the stabilization of hydrogen peroxide bleaching of pulps: an overview. Nord Pulp Pap Res J 21:435-443

Xiao HB, Tao XM, Wang YC, Qian SX, Shi GH, Li H (2008) Dipicolinate as acceptor in D- $\pi-\mathrm{A}$ chromophores: synthesis, characterization and fluorescence following single- and twophoton excitation. Tetrahedron Lett 49:6819-6822 